\title{
Mixed Proton and Electron Conducting Double Perovskite Anodes for Stable and Efficient Tubular Proton Ceramic Electrolysers
}

Einar Vøllestad ${ }^{1,3}$, Ragnar Strandbakke ${ }^{1}$, Mateusz Tarach², David Catalán², Marie-Laure Fontaine $^{3}$, Dustin Beeaff ${ }^{4}$, Daniel R. Clark ${ }^{1,4}$, Jose M. Serra ${ }^{2}$, Truls Norby ${ }^{1, *}$

${ }^{1}$ Department of Chemistry, University of Oslo, FERMiO, Gaustadalléen 21, NO-0349 Oslo, Norway

${ }^{2}$ Instituto de Tecnología Química (Universitat Politècnica de València - Consejo Superior de Investigaciones Científicas), Avenida de los Naranjos s/n.46022 Valencia, Spain

${ }^{3}$ SINTEF Industry, Sustainable Energy Technology, NO-0314 Oslo, Norway

${ }^{4}$ CoorsTek Membrane Sciences AS, Gaustadalléen 21, NO-0349 Oslo, Norway

Hydrogen production from water electrolysis is a key enabling energy storage technology for large scale deployment of intermittent renewable energy sources. Proton Ceramic Electrolysers (PCEs) can produce dry pressurized hydrogen directly from steam, avoiding major parts of cost-driving downstream separation and compression. The development of PCEs has however suffered from limited electrical efficiency due to electronic leakage and poor electrode kinetics. Here, we present the first fully-operational $\mathrm{BaZrO}_{3}$-based tubular PCE, with $10 \mathrm{~cm}^{2}$ active area and a hydrogen production rate above $15 \mathrm{NmL} \cdot \mathrm{min}^{-1}$. The novel steam anode $B a_{1-}$ ${ }_{x} \mathrm{Gd}_{0.8} \mathrm{La}_{0.2+} \mathrm{Co}_{2} \mathrm{O}_{6-\delta}(\mathrm{BGLC})$ exhibits mixed p-type electronic and protonic conduction and low activation energy for water splitting, enabling total polarization resistances below $1 \Omega \cdot \mathrm{cm}^{2}$ at $600^{\circ} \mathrm{C}$ and faradaic efficiencies close to $100 \%$ at high steam pressures. These tubular PCEs are mechanically robust, tolerate high pressures, allow improved process integration, and offer scale-up modularity.

High temperature electrolysers (HTEs) that utilize readily available steam and/or heat (renewable or industrial) as a supplementary energy source provide superior electrical efficiency compared to conventional water electrolysis. ${ }^{1-4}$ HTEs developed to date comprise solid oxide electrolysers (SOEs) which utilize oxide ion conducting electrolytes and therefore produce hydrogen on the steam side cathode. The undiluted high pressure oxygen produced on the anode in SOEs presents a safety hazard. Their high operating temperature (typically $800^{\circ} \mathrm{C}$ ) 
imposes challenges in terms of cell degradation, expensive construction materials, and constrained process integration. ${ }^{4-6}$ Operation at temperatures below $700^{\circ} \mathrm{C}$ would reduce degradation and enable the utilization of inexpensive stainless steel materials in manifolds and housing for pressurized systems. ${ }^{7}$

Proton ceramic electrolysers (PCEs) based on proton conducting electrolytes such as Y-doped $\mathrm{BaZrO}_{3}-\mathrm{BaCeO}_{3}$ solid solutions (BZCY) conversely transport protons $\left(\mathrm{H}^{+}\right)$from the steam anode to the hydrogen-side cathode. Protons migrate with lower migration barrier than oxide ions, and are thus favourable for operation at intermediate temperatures, e.g. $400-700^{\circ} \mathrm{C}$, which is suitable for integration with renewable heat sources (solar-thermal and geothermal plants), and waste heat from industrial plants. Unlike other electrolysers it hence produces directly dry electrochemically pressurized $\mathrm{H}_{2}$ at the cathode while the $\mathrm{O}_{2}$ produced at the anode is diluted with steam (Figure 1a) ${ }^{8-11}$ This reduces the risks of handling undiluted oxygen at high pressure and temperature and, more importantly, alleviates the necessity for most of the cost-driving downstream separation and mechanical multi-step compression of $\mathrm{H}_{2}$, amounting for instance to approximately 2.4 and $3 \mathrm{kWh} / \mathrm{kg} \mathrm{H}_{2}$ at $600^{\circ} \mathrm{C}$ for compression ratios of 10 and 20, respectively. PCEs instead offer the direct production of pressurized $\mathrm{H}_{2}$ from low-pressure steam, and the associated compression heat - generally dissipated - can be locally utilized in the endothermic electrolysis reaction at the cathode, in turn giving rise to higher process energy efficiency. 


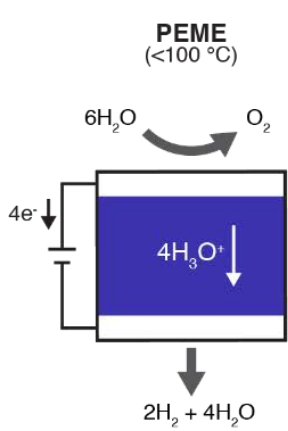

b

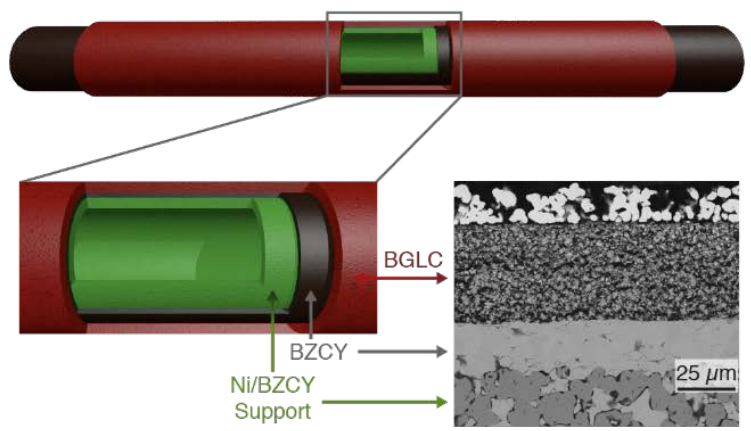

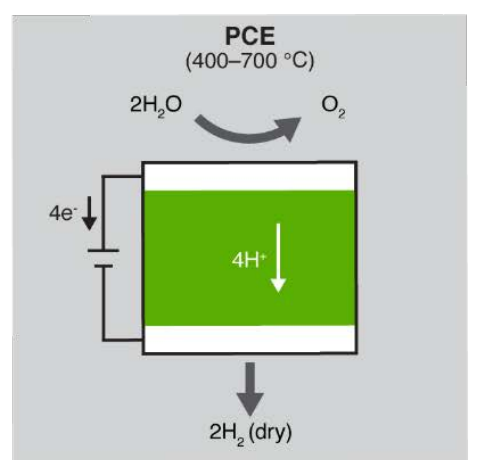

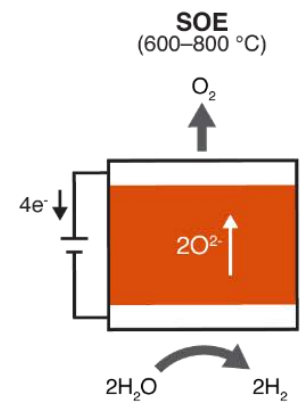

c

1. Water adsorption 2. Incorporation

3. Oxygen release/proton transfer

4. Proton reduction

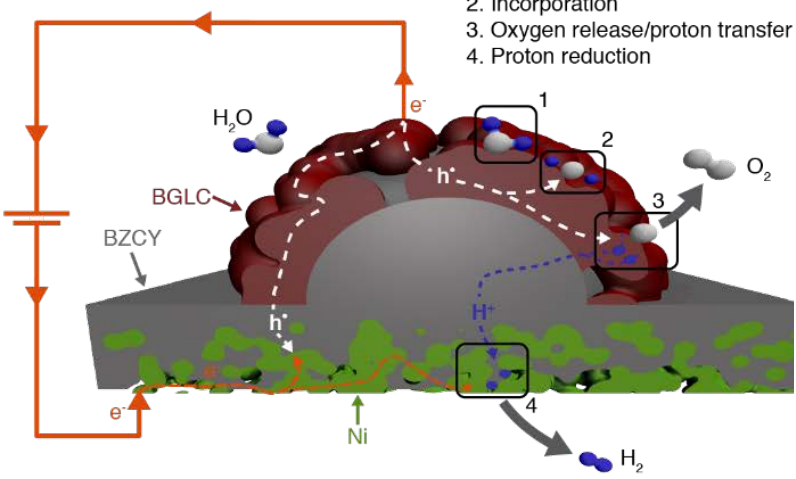

Figure 1: Schematics of water electrolysis technologies and PCE membrane and transport. a, Comparison of PEME, PCE and SOE operation, illustrating the benefit of PCEs with production of undiluted dry hydrogen on the cathode and diluted oxygen on the anode. b, Illustrations of a tubular PCE architecture producing dry hydrogen in the inner cathode chamber with scanning electron micrograph of a polished cell architecture. c, Detailed view of transport phenomena and reaction mechanisms through a PCE.

The promise of proton ceramic technologies have recently been demonstrated for highly performing and fuel-flexible fuel cells (PCFCs), ${ }^{12-15}$ tubular proton ceramics for direct methane conversion into benzene ${ }^{16}$ and intensified steam methane reforming. ${ }^{17}$ However, reports of steam electrolysis are scarce and limited to laboratory-scale button cells $\left(<1 \mathrm{~cm}^{2}\right)$ mostly with moderate performance and low efficiencies (40-60\%). ${ }^{18-22}$ So far, a lack of efficient and stable steam anodes have caused high overpotentials that impose increased p-type electronic conductivity in the BZCY electrolyte, resulting in reduced faradaic efficiency as a consequence of electronic leakage currents, typically below 50\%. A concurrent article ${ }^{15}$ reports high efficiencies of PCEs for small button cells employing a doubly-doped $\mathrm{BaCeO}_{3}$-based electrolyte (BaCe $\left.\mathrm{Ba}_{0.7} \mathrm{Zr}_{0.1} \mathrm{Y}_{0.1} \mathrm{Yb}_{0.1} \mathrm{O}_{3-\delta}, \quad \mathrm{BCZYYb}\right)$ and $\mathrm{BaCo}_{0.4} \mathrm{Fe}_{0.4} \mathrm{Zr}_{0.1} \mathrm{Y}_{0.1} \mathrm{O}_{3-\delta}$ (BCFZY) anode operating at sub-atmospheric steam pressures. Herein, we show how materials-specific challenges can be addressed and overcome, especially concerning targeted adjustment of the 
anode material composition, to reach stable operation and efficiencies close to $100 \%$ for tubular PECs (Figure 1) with large $\left(10 \mathrm{~cm}^{2}\right)$ electrode area at high steam pressures.

The anode activity towards the electrochemical oxygen-steam redox reaction can be enhanced by extending the reaction zone beyond the triple phase boundaries (tpb) through the use of mixed protonic electronic conductors (MPECs) as electrode material (Figure 1c). For a long time, materials that combine mixed protonic and electronic conduction with high catalytic activity and thermodynamic stability have been notoriously elusive. However, recent efforts have led to the discovery of electronically conductive perovskite-based materials that exhibit proton incorporation in the presence of steam. ${ }^{13,23-26}$ Among these, the double perovskite $\mathrm{BaGd}_{0.8} \mathrm{La}_{0.2} \mathrm{Co}_{2} \mathrm{O}_{6-\delta}$ (BGLC) exhibits the lowest apparent polarisation resistance reported for proton ceramic cells of $0.05 \Omega \cdot \mathrm{cm}^{2}$ at $650^{\circ} \mathrm{C}$ in a symmetrical cell with wet air $\left(E_{A}<50 \mathrm{~kJ} \cdot \mathrm{mol}^{-}\right.$ ${ }^{1}$ ) for the oxygen-steam redox reaction, and an electronic conductivity higher than $800 \mathrm{Scm}^{-}$ ${ }^{124,27,28}$ BGLC is an ordered double perovskite with oxygen vacancies preferentially located in the lanthanide-layer, and displays considerable proton incorporation in humid atmospheres. ${ }^{24}$ A recent molecular dynamics study ${ }^{29}$ of a similar compound, $\mathrm{BaGdCo}_{2} \mathrm{O}_{5+\delta}$, revealed fast proton diffusion kinetics within the a-b plane, supporting the mixed protonic conduction character of BGLC electrodes. For the purpose of high pressure electrolysis, where the anode material is exposed to high $p \mathrm{H}_{2} \mathrm{O}$, we tailored the composition of BGLC by partial substitution of $\mathrm{Ba}$ with $\mathrm{La}$, giving the general formula $\mathrm{Ba}_{1-x} \mathrm{Gd}_{0.8} \mathrm{La}_{0.2+} \mathrm{Co}_{2} \mathrm{O}_{6-\delta}$. Stability tests at $600^{\circ} \mathrm{C}$ under 1.5 bar of steam for 72 hours showed a separation into two phases for compositions with $x<0.5$, i.e., a double perovskite phase and hexagonal $\mathrm{BaCoO}_{3}$ (Supplementary Information (SI) Fig.1). ${ }^{30}$ Precipitation of $\mathrm{BaCoO}_{3}$ proceeds until the remaining double perovskite phase reaches a composition stable in steam, thereafter the two phases coexist under the given conditions (Figure 2). The stable double perovskite phase is expected to have both of the two lanthanides substituted for Ba. Indeed, XRD analysis shows that when $50 \%$ of the Ba is substituted with La $(\mathrm{x}=0.5)$, BGLC is stable in 1.5 bar of steam, with no precipitation of $\mathrm{BaCoO}_{3}$. The excellent stability in high steam atmospheres was further confirmed at a pressure of 28 barg (75\% steam $25 \% \mathrm{O}_{2}$ ) at $600^{\circ} \mathrm{C}$ with no evidence of secondary phase formation (SI Fig. 1c). 


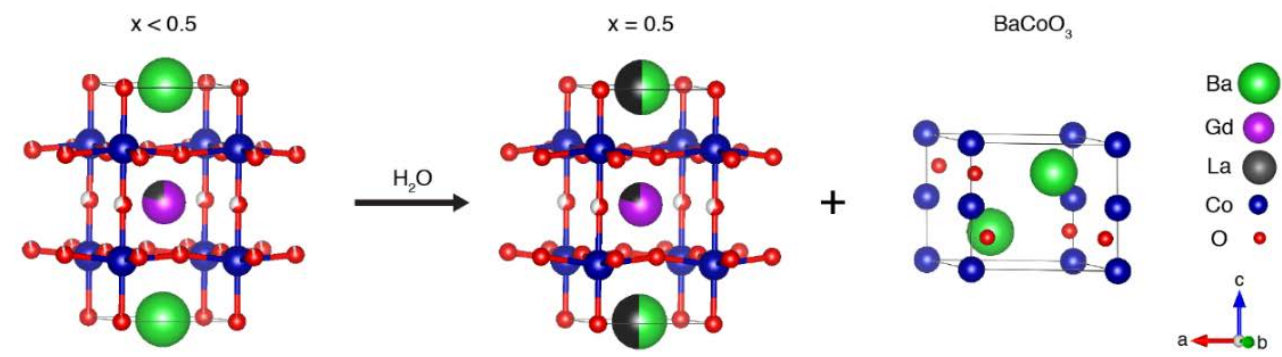

b

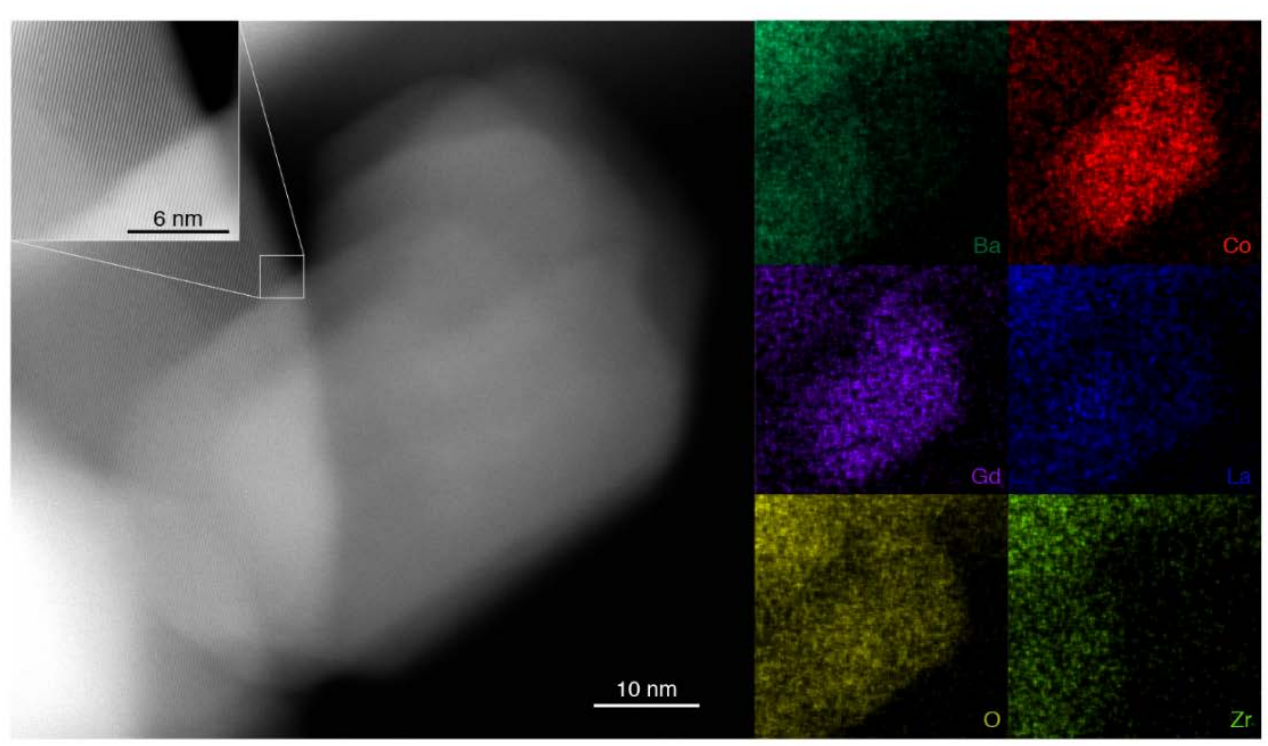

Figure 2: Phase segregation and microscopy of BGLC. a, Phase segregation and stability of BGLC in 1.5 bar of steam and $600^{\circ} \mathrm{C}$ after 72 hours. b, S/TEM analysis of BGLC nanoparticle after operation as steam anode. High-angle annular dark-field (HAADF) micrograph on the left with corresponding energy dispersive x-ray spectroscopy (EDS) maps of Ba, Co, Gd, La, O and Zr. High-resolution S/TEM micrograph of interface in the top left.

Tubular PCEs were assembled by brush-painting $30 \mu \mathrm{m}$-thick BGLC-based anodes on $6 \mathrm{~cm}$ long tubular BZCY-NiO/BZCY half-cells. The half-cells were produced by co-sintering spraycoated BZCY electrolyte on extruded Ni/BZCY cathode support tube using solid-state reactive sintering. ${ }^{31}$ This method ensures a reproducible, cost-efficient and highly scalable ${ }^{16,17}$ production route of open-ended tubular segments with 5-12 $\mathrm{cm}^{2}$ active area. BZCY72 $\left(\mathrm{BaZr}_{0.7} \mathrm{Ce}_{0.2} \mathrm{Y}_{0.1} \mathrm{O}_{2.95}\right)$ was chosen as the electrolyte composition as a compromise between thermodynamic stability (high Zr content) and low grain boundary resistance (high Ce content). Composite BGLC/BZCY anodes were also employed to tailor the macroscopic thermal expansion of the electrode layer to better match that of the tubular support, which is critical to achieve sufficient attachment and mechanical integrity in tubular systems during thermal cycling. Figure 1b shows a schematized cell arrangement and a detailed SEM view of the electrodes-electrolyte interfaces and the top noble metal current collector. BGLC and BZCY 
phases are chemically compatible as confirmed by XRD analysis of co-fired powders and form clean grain interfaces, as revealed by S/TEM analysis of composite anodes after electrolysis tests at high steam pressures (Figure 2b).

Figure 3a displays current-voltage behaviour of cells operated under electrolytic bias at a total

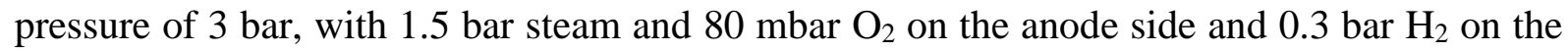
cathode side (Ar as balance on both sides) at $600^{\circ} \mathrm{C}$. The cells with the composite anode displayed the lowest total area-specific resistance (ASR) under operation, and much higher faradaic efficiencies. Electrochemical impedance analysis under slight electrolytic bias (Figure 3b) reveals a significantly lower electrode polarization resistance $\left(R_{\mathrm{p}}\right)$ for the composite anode $\left(0.8 \Omega \cdot \mathrm{cm}^{2}\right)$ as compared to the single-phase BGLC anode $\left(4 \Omega \cdot \mathrm{cm}^{2}\right)$. Post-measurement inspections of the single-phase BGLC anode revealed considerable delamination of the electrode layer, and the larger impedance of this cell is thus attributed to poor adhesion and limited reaction zone between the electrode and electrolyte resulting from TEC-mismatch between BGLC and the Ni/BZCY support tube. This was successfully mitigated by using composite anodes, where a combination of higher annealing temperature and improved TECmatching with the tubular support ensured a mechanically robust electrode layer with good adhesion to the electrolyte. 
a

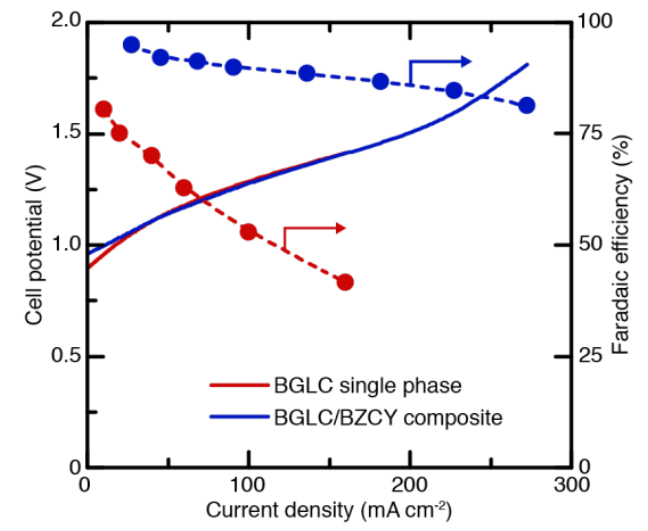

b

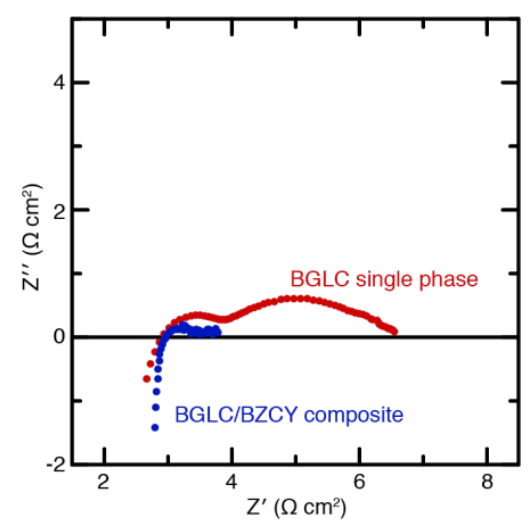

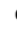

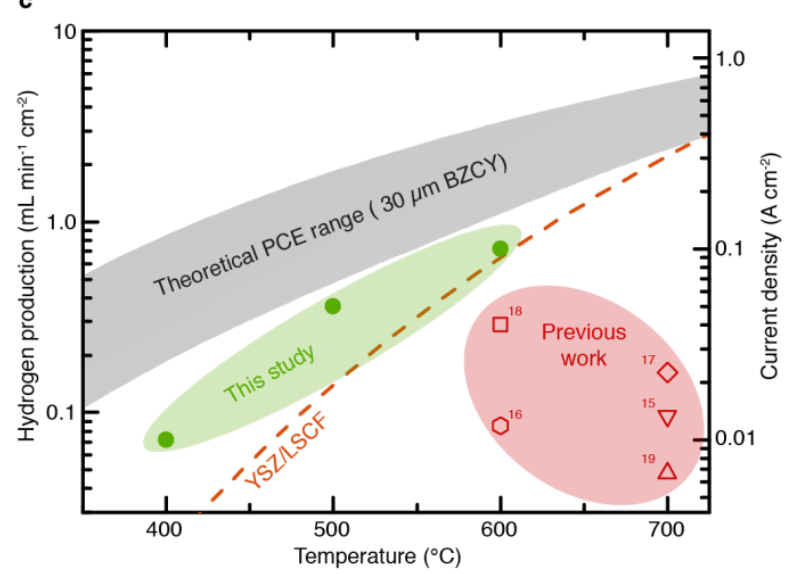

Figure 3: PCE electrochemical performance and literature comparison. a, Current-voltage curves and faradaic efficiency of two different PCEs (cells 1 and 2, see SI) measured at $600^{\circ} \mathrm{C}$ with $1.5 \mathrm{bar}$ steam in the anode compartment. b, Corresponding Nyquist plots of the two cells under a small electrolytic bias. c, Hydrogen production rates and ionic current densities at thermo-neutral voltage $(1.29 \mathrm{~V})$ compared to literature values calculated from reported area specific resistances and faradaic efficiencies. The grey area provides the theoretical range of operation for PCEs considering a $30 \mu \mathrm{m}$ thick BZCY electrolyte with BGLC anode. The dashed line represents predicted SOE performance using $30 \mu \mathrm{m}$ thick YSZ electrolyte with LSCF anode.

The polarisation resistance of the composite anode cell under electrolytic operation is below $1 \Omega \cdot \mathrm{cm}^{2}$ for anode and cathode combined at $600^{\circ} \mathrm{C}$ with an activation energy of $0.4 \mathrm{eV}$ between 400 and $700^{\circ} \mathrm{C}$ (SI, Fig. 11) attributed primarily to the BGLC steam anode. The rate limiting step for the water splitting anode reaction is ascribed to surface-related processes (adsorption, dissociation and diffusion) as inferred from the capacitance values of $10^{-4}-10^{-2} \mathrm{~F} \cdot \mathrm{cm}^{-2}$, in agreement with our previous work on BGLC. ${ }^{24}$ In addition, gas phase diffusion resistance (with associated capacitances of $1-10 \mathrm{~F} \cdot \mathrm{cm}^{-2}$ ) accounts for around $1 / 3$ of $R_{\mathrm{p}}$ at $600^{\circ} \mathrm{C}$. Upon increasing electrolytic bias, however, gas diffusion resistance diminishes, indicating that consumption and thereby reduction of $\mathrm{H}_{2} \mathrm{O}$ levels facilitate desorption and diffusion of the formed molecular oxygen, i.e., that high steam pressures correspondingly cause oxygen mass transfer limitations 
at low currents. The ohmic resistance is a major contributor to the total cell resistance, and includes also parasitic contact and current collection resistances resulting from the large electrode area of the measurement setup and tubular geometry. ASR values are given without scaling parasitic wiring and contact resistances to the total area (see SI for details). The robustness of the composite electrode processing was further investigated across four cells employing different current collection and manufacturing process, showing only small variations in electrode polarization (cf. SI Fig. 3). There were, however, significant differences in the ohmic offset of the cells due to parasitic and contact resistances arising from the different current collection approaches, highlighting the challenge of current collection along the length of tubular electrochemical cells.

By implementing stable BGLC and BZCY compositions as the anode and electrolyte materials, we have been able to produce fully operational PCEs with larger surface areas $\left(>10 \mathrm{~cm}^{2}\right)$ that can be operated close to $100 \%$ faradaic efficiency at $500-600^{\circ} \mathrm{C}$ under high steam pressures. The $\mathrm{H}_{2}$-production rates of these tubular cells under thermo-neutral operation (1.29 V) exceed those in the literature using small button-cell BZY-based PCEs, as shown in Figure 3c. ${ }^{18-22} \mathrm{H}_{2}$ production rates obtained in this work approach the predicted range of PCE operation considering a $30 \mu \mathrm{m}$ thick BZCY and BGLC as the anode ${ }^{24,27}$ and surpass that of SOE operation below $700^{\circ} \mathrm{C}$ with YSZ and LSCF as the electrolyte and anode, respectively (See SI for details). ${ }^{32-34}$ Further reduction in ASR for increased $\mathrm{H}_{2}$ production can be obtained through improvement of current collection along the tube length to reduce ohmic contact resistances, reduction of electrolyte thickness, and optimization of the electrolyte composition with higher Ce-content and dopant concentration and hence higher proton conductivity, e.g. BaCe $_{0.7} \mathrm{Zr}_{0.1} \mathrm{Y}_{0.1} \mathrm{Yb}_{0.1} \mathrm{O}_{3-\delta}(\mathrm{BCZYYb})$ or similar. ${ }^{15}$

The reported hydrogen production rates of button-cell electrolysers in the literature deviate significantly from the theoretical performance of PCEs, ${ }^{18-22}$ principally due to low faradaic efficiencies $\left(\eta_{F}<50 \%\right)$ originating from severe p-type electronic leakage through the electrolyte induced by large anode overpotentials. To illustrate the issue of leakage currents, the transport of the protonic and electronic (holes and electrons) charge carriers can be understood to proceed in "rails" connected in parallel (Figure 1c and SI Fig. 10) where each carrier displays a particular dependency on cell potential, temperature and partial pressures. In these rails, protons must overcome three in-series connected resistances - ascribed to anode, electrolyte and cathode - while electronic charge carriers depend on the electronic conductivity in the electrolyte only. 
Imposing higher current densities in electrolysis operation leads to higher cell potentials that in turn induces the generation of additional p-type electronic charge carriers in the electrolyte on the anode interface. ${ }^{35} 36$ In proton conducting BZCY ceramics, the concentration of electron holes can be related to oxygen and steam partial pressures and the redox potential $E$ through the water oxidation equilibrium as

$$
\left[\mathrm{h}^{\bullet}\right]=K_{\mathrm{OX}}\left[\mathrm{OH}_{\mathrm{O}}^{\bullet}\right] p_{\mathrm{H}_{2} \mathrm{O}}^{-\frac{1}{2}} p_{\mathrm{O}_{2}}^{\frac{1}{4}}=K_{\mathrm{ox}} \exp \left(\frac{F\left(E-E^{0}\right)}{R T}\right)
$$

, assuming full hydration of BZCY $\left(\left[\mathrm{OH}_{\mathrm{O}}^{\bullet}\right]=\left[\mathrm{Y}_{\mathrm{Zr}}^{/}\right]\right)$. Thus, operation of a PCE anode at high potentials effectively enhances the electronic leakage current (and lowers faradaic efficiency $\left.\eta_{F}\right)$. Similarly, increased n-type conduction develops on the cathode-electrolyte interface as the cathode overpotential increases and the effective hydrogen pressure is increased.

High-steam pressure operation will shift the equilibrium towards lower electron hole concentration, higher proton concentration, and thus a higher ionic transport number near the anode. At a fixed steam utilization rate, increased total pressure should diminish the hole concentration with a $p_{\text {tot }}^{-1 / 4}$-dependency, giving rise to higher efficiency $\eta_{F}$. Lower temperature increases the efficiency further due to decreased hole and increased proton concentrations, helped by the low activation energy for water oxidation by the BGLC anode, as illustrated in Figure 4a, where $\mathrm{I}-\mathrm{V}$-characteristics and $\mathrm{H}_{2}$ production rates at 500,600 , and $700^{\circ} \mathrm{C}$ are presented for the composite anode cell. 

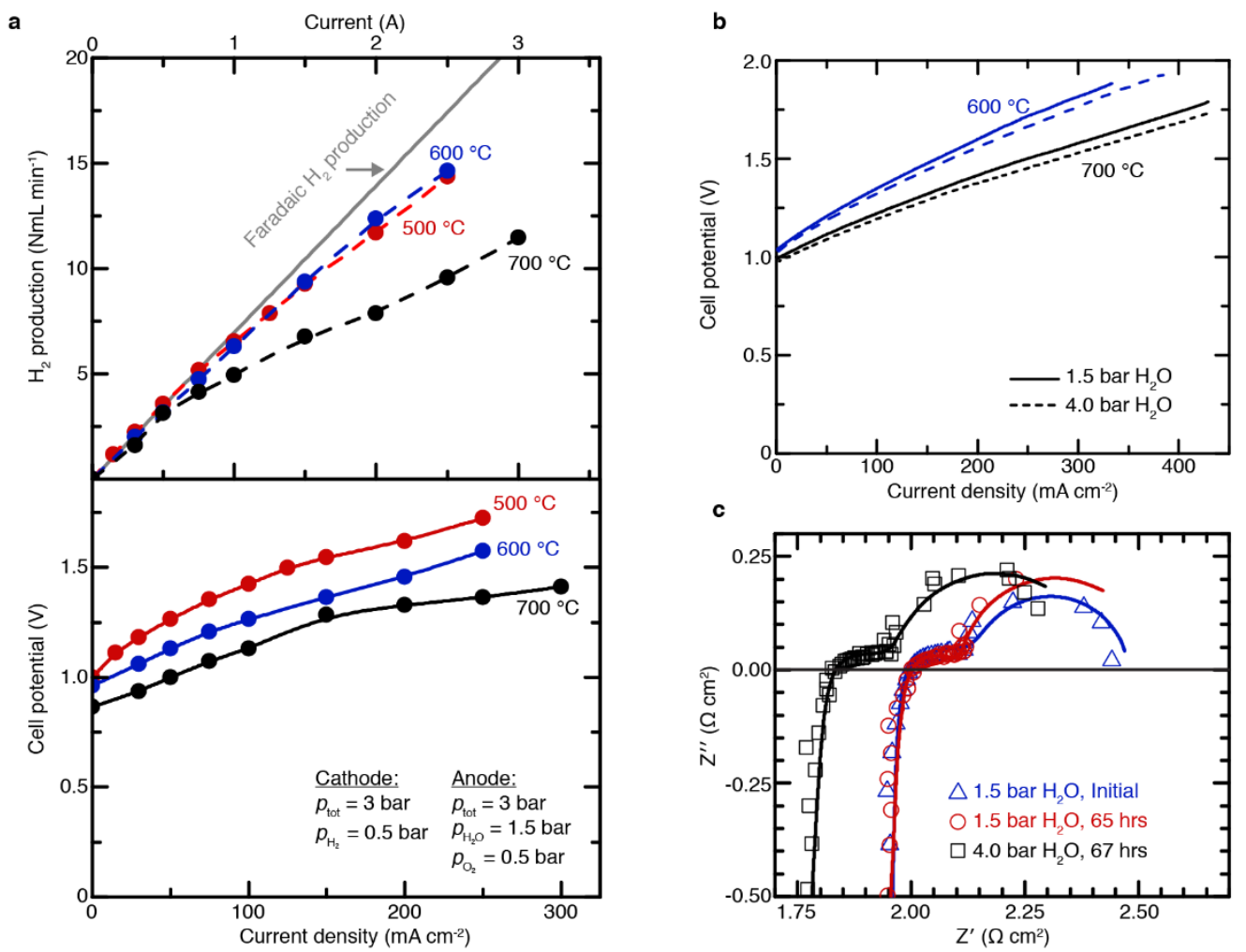

Figure 4: PCE cell performance and characterization. a, Hydrogen production and current-voltage relations of a composite-anode cell (cell 2) at 500,600 and $700^{\circ} \mathrm{C}$ operated at 1.5 bar steam. b, Currentvoltage relations (cell 4) at 600 and $700{ }^{\circ} \mathrm{C}$ in 1.5 and 4 bar steam using a $10 \mathrm{~cm}^{2}$ composite anode. c, Impedance sweeps at $700^{\circ} \mathrm{C}$ and 1.5 bar steam at zero and 65 hours (cell 4), and under 4 bar steam after 67 hours of operation.

The positive effect of higher steam (and total) pressure is observed in the I-V curves recorded for a composite anode cell under 1.5 and 4 bar steam on the anode side (Figure $4 \mathrm{~b}$ ) and keeping constant $\mathrm{pO}_{2}$ and $\mathrm{pH}_{2}$ on anode and cathode side, respectively. The operating voltage is decreased by $30-50 \mathrm{mV}$ when the steam pressure is increased from 1.5 bar to 4 bar, reflecting an increased proton conductivity in the electrolyte, as inferred from the Nyquist plots presented in Figure 4c. The stability of the electrochemical performance after 65 hours of high-steam pressure operation is evidenced in the same figure.

The long-term stability of a tubular cell with BGLC/BZCY composite anode was further evaluated under pressurized electrolysis conditions (Figure 5a), showing excellent stability over 700 hours of operation at $600^{\circ} \mathrm{C}$ with constant current density of $62.5 \mathrm{~mA}^{\cdot} \mathrm{cm}^{-2}$ and $1.5 \mathrm{bar}$ steam on the anode. The small variations and spikes in the cell potential are associated with temperature and pressure changes that occurred upon refilling the steam-supply water tank. 
During operation, the $\mathrm{pH}_{2} \mathrm{O}$ gradient over the cell will lead to a certain steam permeation due to ambipolar transport of protons and oxide ions, counteracted by the co-ionic migration of oxide ions towards the $\mathrm{O}_{2} / \mathrm{H}_{2} \mathrm{O}$-side of the cell in electrolysis mode. The balance between ambipolar diffusion and co-ionic transport by oxide ions will establish a small water vapour partial pressure in the $\mathrm{H}_{2}$ compartment, depending on the oxide ion transport number (i.e., $T$ and $\mathrm{pH}_{2} \mathrm{O}$ ), ensuring hydration of the electrolyte there. The humidity in the $\mathrm{H}_{2}$ exhaust gas stream from a cell operated at $600^{\circ} \mathrm{C}$ with 1.5 bar steam on the anode side was measured as a function of current density to evaluate water content in the produced hydrogen for the present cell and reactor design, shown in Figure 5b. As can be seen, the humidity of the produced hydrogen remains low (around $0.24 \%$ ) and unchanged during whole test independently of applied current density. This illustrates a major advantage of PCEs over SOEs, where the steam is a major component of the hydrogen-side atmosphere.

The energy efficiency of hydrogen production using tubular PCEs is presented as a function of current density in Figure 5c with four different assumptions; i) strict cell-level electrical efficiency assuming surplus free heat available, ii) energy efficiency including heat demand in endothermic operation, iii and iv) energy efficiency including water vaporization at $50 \%$ and 90\% steam utilization, respectively. The present tubular PCEs with active area of $12 \mathrm{~cm}^{2}$ provide cell-level energy efficiencies above $80 \%$ at $150 \mathrm{~mA} \cdot \mathrm{cm}^{-2}$. From a technological perspective, it is needed to reduce the ohmic losses throughout the cell to yield similar efficiencies at current densities above $1 \mathrm{~A} \cdot \mathrm{cm}^{-2}$. 

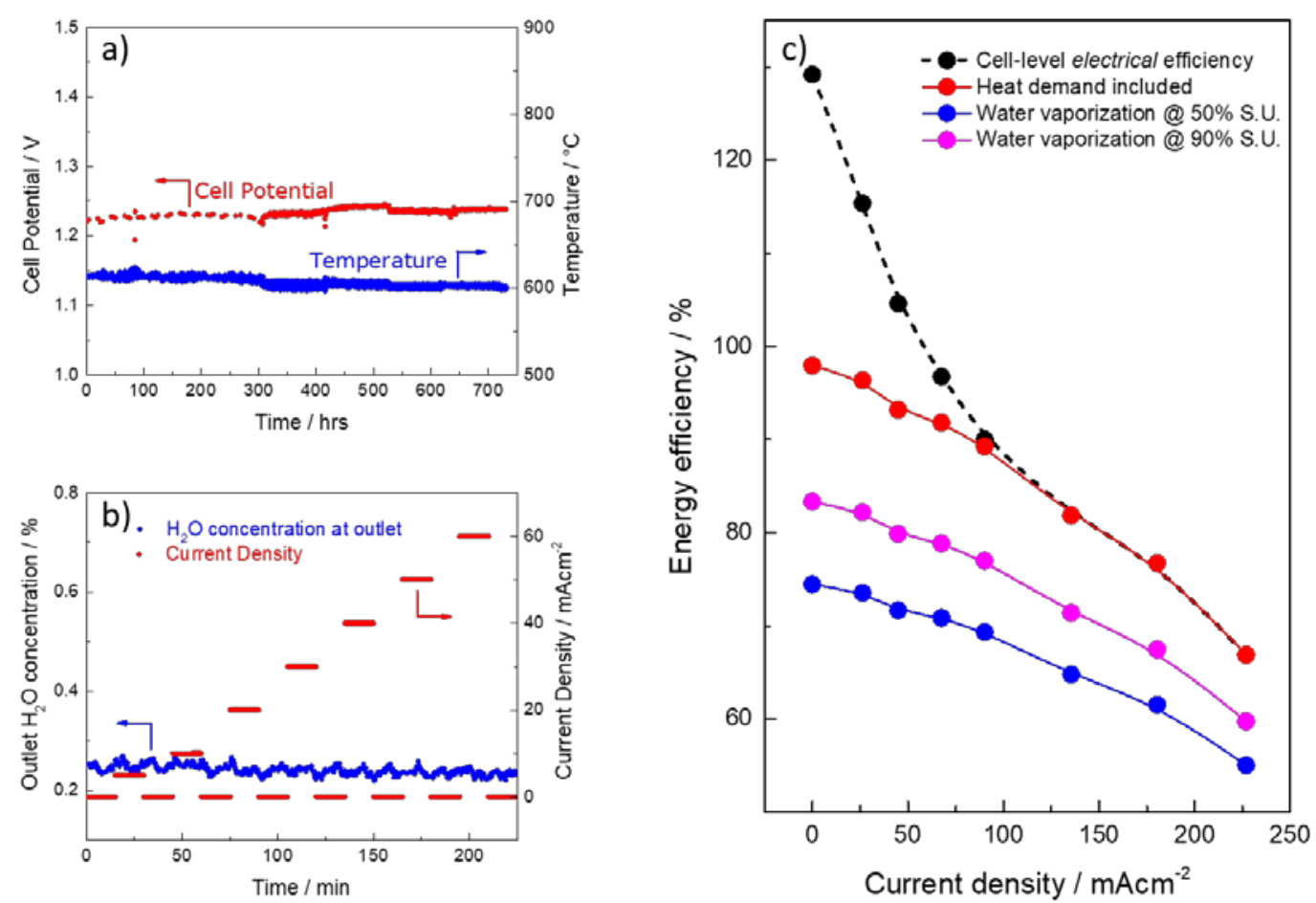

Figure 5: Technological viability of tubular PCEs. a) Stability of tubular PCE (cell 5) operated at 3 bar total pressure with 1.5 bar steam on anode side over 700 hours at $600^{\circ} \mathrm{C}$ with a constant current density of $62.5 \mathrm{~mA} \cdot \mathrm{cm}^{-2}$. b) Water content in hydrogen exhaust stream as a function of current density, showing less than $0.3 \%$ water for all applied current densities. c) Calculated energy efficiencies at celllevel and including heat of water vaporization based on the present set of results.

To validate the observed positive effects of lowered $R_{\mathrm{p}}$ and higher pressure on the faradaic efficiency $\eta_{F}$ of PCEs, a model is developed based on defect chemistry (Eq.1) and the ButlerVolmer relation for the electrode polarization. This model describes partial ionic and electronic currents as a function of cell potential (cf SI for details) with parameters from the literature for BZCY to describe transport through the electrolyte. The anode polarization resistance and total pressure (at a fixed steam utilization rate) are varied to investigate the effect of electrode performance and operating conditions. Figure 6a shows how the predicted faradaic efficiency increases significantly with decreasing $R_{\mathrm{p}}$ for a given current density, as the lower overpotential reduces the electron hole concentration in the electrolyte. The model also predicts increased faradaic efficiency at higher total pressures (Figure 6b) for a given steam utilization (SU) and charge transfer resistance. Thus, pressurized PCE operation allows improved performance and 
electrical efficiency and - contrary to conventional electrolysers - enable the production of dry electrochemically pressurized hydrogen directly in the cathode compartment without dilution with unreacted steam (SOE) or water drag (PEM) (Figure 1a).

Computational fluid-dynamics (CFD) modelling further reveals that the tubular design employed in this work allows for essentially isothermal operation along the entire tube length (Figure 6c-e). Furthermore, there are practically no radial concentration gradients, i.e. the proper gas-phase transport for the chosen cell geometry is confirmed, while the spatiallyprogressive steam conversion and dilution with the formed oxygen can be recognized (Figure 6f). Sensitivity analysis of the current density illustrates the transition between endo- and exothermic regimes along the cell length (SI Fig. 13a). The extended analysis on $29 \mathrm{~cm}-$ long cells - single or in-series segmented - shows again an isothermal profile along the tube length and absence of compositional gradients (SI Fig. 14a). These CFD results demonstrate that the electrolysis process is scalable for tubular PCE cells with beneficial heat and process integration.

To conclude, BGLC-based PCEs can be operated at a lower temperature and high faradaic efficiency, while the tubular geometry enables simple heat and process integration as well as low-cost cell fabrication and peripherals. As a consequence, the results presented herein demonstrate the potential of PCE technology as a cost-competitive alternative for large-scale energy storage and pressurized hydrogen production, especially when renewable or industrial waste heat is available. 

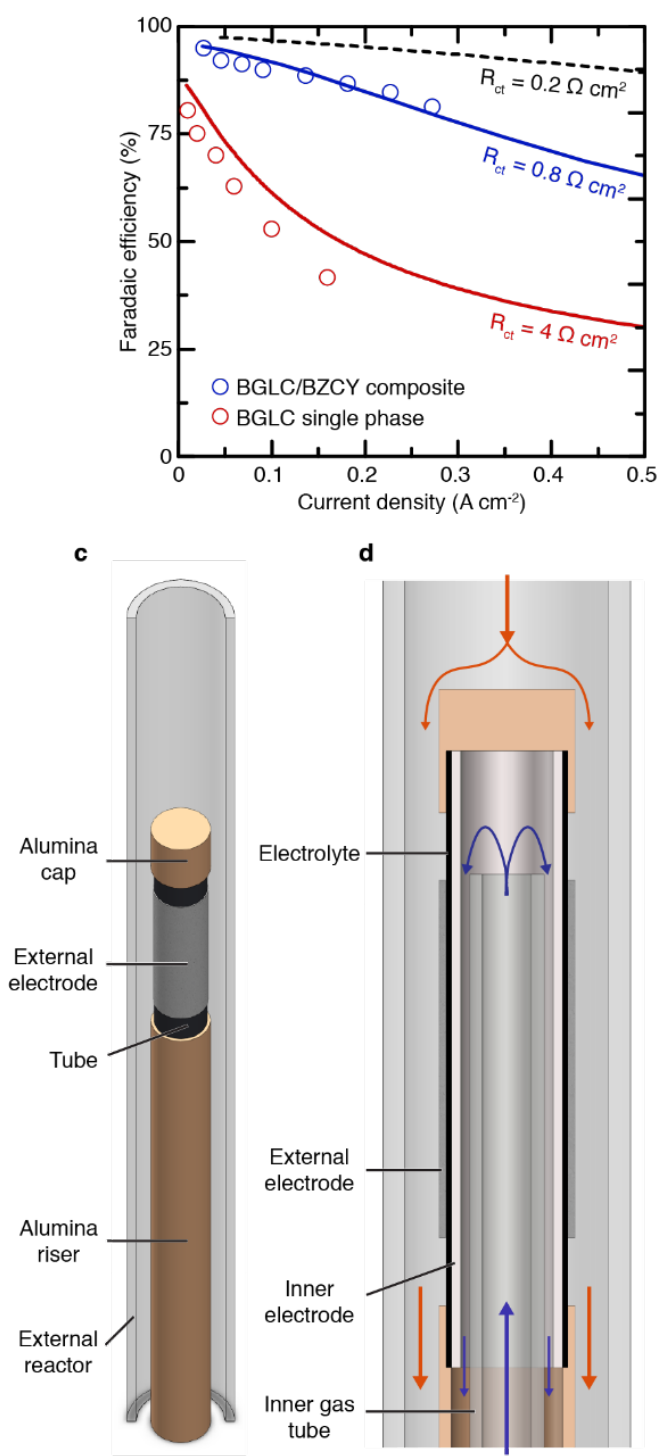

d

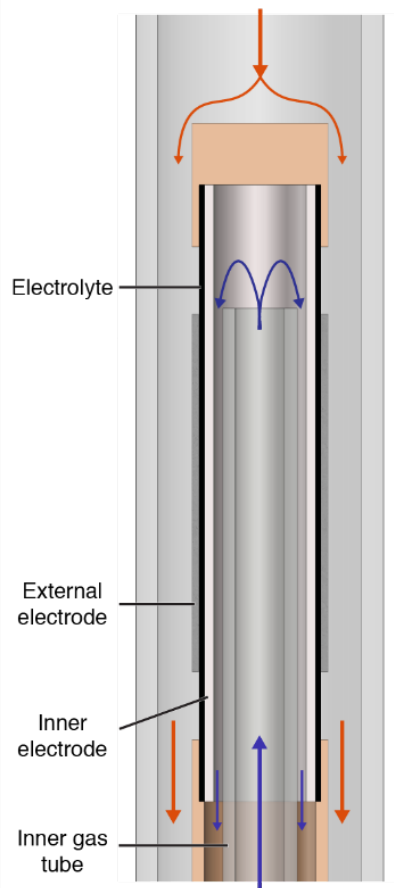

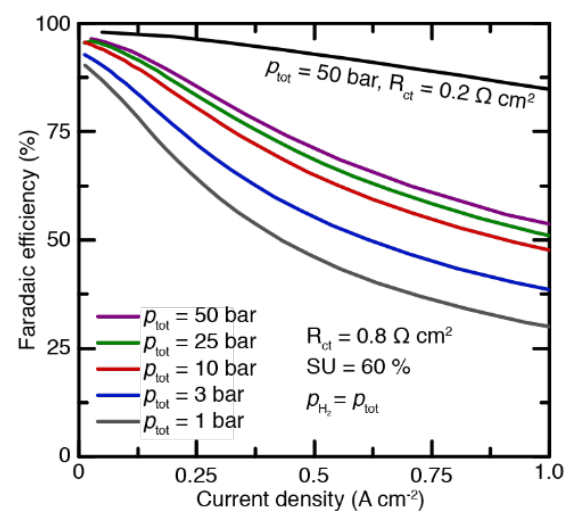

e

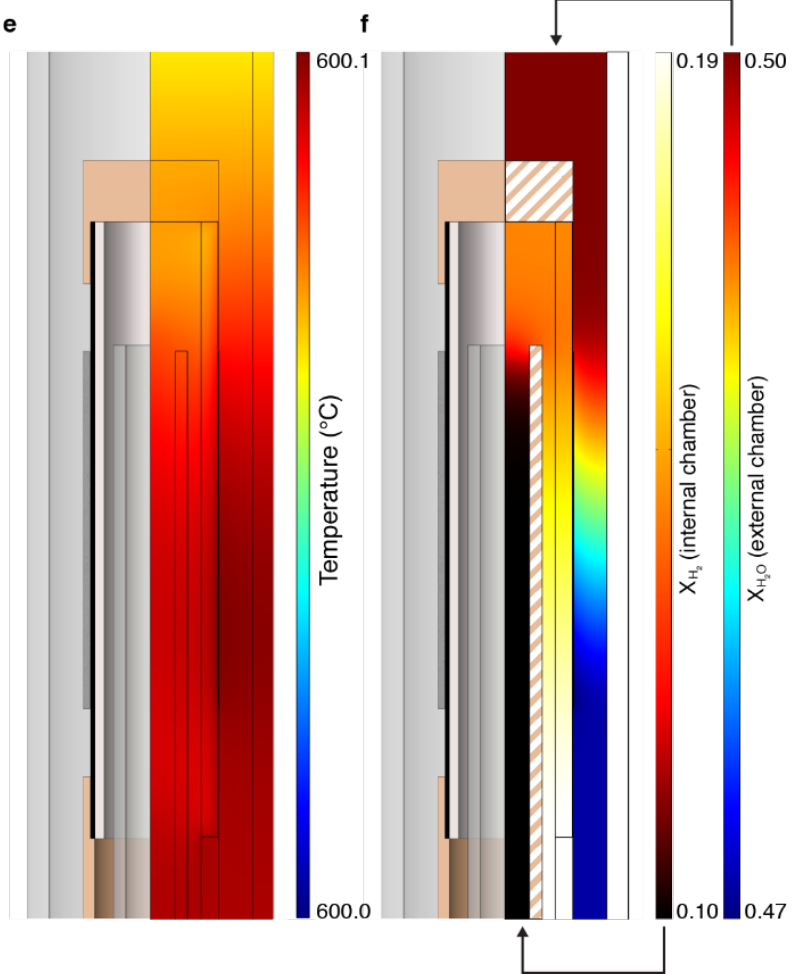

Figure 6: Charge transfer and CFD models of PCE system. Predicted faradaic efficiencies using Eq.1 (lines) as a function of charge transfer resistance (a) and total system pressure (b). The symbols in (a) represent the measured values for the single-phase and composite PCEs in this work. Results of the adiabatic CFD model are depicted in figures c-g. c, Description of the setup; d, Cross-section of the setup centered in the tube with a description of the external gas flow (orange arrows), and internal gas flow (blue arrows); e, Temperature profile for the reference case near the thermoneutral point; $\mathbf{f}$, Molar fraction profiles for hydrogen in the internal chamber and for steam in the external chamber.

\section{References:}

1 Hauch, A., Ebbesen, S. D., Jensen, S. H. \& Mogensen, M. Highly efficient high temperature electrolysis. Journal of Materials Chemistry 18, 2331-2340 (2008).

2 Laguna-Bercero, M. Recent advances in high temperature electrolysis using solid oxide fuel cells: A review. Journal of Power Sources 203, 4-16 (2012). 
3 Ebbesen, S. D., Jensen, S. H., Hauch, A. \& Mogensen, M. B. High temperature electrolysis in alkaline cells, solid proton conducting cells, and solid oxide cells. Chemical reviews 114, 10697-10734 (2014).

4 Knibbe, R., Traulsen, M. L., Hauch, A., Ebbesen, S. D. \& Mogensen, M. Solid Oxide Electrolysis Cells: Degradation at High Current Densities. Journal of The Electrochemical Society 157, B1209-B1217, doi:10.1149/1.3447752 (2010).

5 Hauch, A., Jensen, S. H., Ramousse, S. \& Mogensen, M. Performance and Durability of Solid Oxide Electrolysis Cells. Journal of The Electrochemical Society 153, A1741A1747, doi:10.1149/1.2216562 (2006).

6 Wachsman, E. D. \& Lee, K. T. Lowering the Temperature of Solid Oxide Fuel Cells. Science 334, 935-939, doi:10.1126/science.1204090 (2011).

7 Ishihara, T., Jirathiwathanakul, N. \& Zhong, H. Intermediate temperature solid oxide electrolysis cell using $\mathrm{LaGaO}_{3}$ based perovskite electrolyte. Energy \& Environmental Science 3, 665-672 (2010).

8 Iwahara, H., Uchida, H. \& Maeda, N. High temperature fuel and steam electrolysis cells using proton conductive solid electrolytes. Journal of Power Sources 7, 293-301 (1982).

9 Norby, T. in Perovskite oxide for solid oxide fuel cells Fuel Cells and Hydrogen Energy (ed T. Ishihara) 217-241 (Springer, 2009).

10 Tong, J., Clark, D., Bernau, L., Sanders, M. \& O'Hayre, R. Solid-state reactive sintering mechanism for large-grained yttrium-doped barium zirconate proton conducting ceramics. Journal of Materials Chemistry 20, 6333-6341 (2010).

11 Iwahara, H., Yajima, T., Hibino, T., Ozaki, K. \& Suzuki, H. Protonic conduction in calcium, strontium and barium zirconates. Solid State Ionics 61, 65-69 (1993).

12 Duan, C. et al. Readily processed protonic ceramic fuel cells with high performance at low temperatures. Science 349, 1321-1326 (2015).

13 Choi, S. et al. Exceptional power density and stability at intermediate temperatures in protonic ceramic fuel cells. Nature Energy, doi:10.1038/s41560-017-0085-9 (2018).

14 An, H. et al. A $5 \times 5 \mathrm{~cm} 2$ protonic ceramic fuel cell with a power density of $1.3 \mathrm{~W} \mathrm{cm-}$ 2 at $600{ }^{\circ} \mathrm{C}$. Nature Energy, doi:10.1038/s41560-018-0230-0 (2018).

15 Duan, C. et al. Highly efficient reversible protonic ceramic electrochemical cells for power generation and fuel production. Nature Energy 4, 230-240, doi:10.1038/s41560019-0333-2 (2019).

16 Morejudo, S. et al. Direct conversion of methane to aromatics in a catalytic co-ionic membrane reactor. Science 353, 563-566 (2016).

17 Malerød-Fjeld, H. et al. Thermo-electrochemical production of compressed hydrogen from methane with near-zero energy loss. Nature Energy, doi:10.1038/s41560-0170029-4 (2017).

18 Babiniec, S. M., Ricote, S. \& Sullivan, N. P. Characterization of ionic transport through $\mathrm{BaCe}_{0.2} \mathrm{Zr}_{0.7} \mathrm{Y}_{0.1} \mathrm{O}_{3-\delta}$ membranes in galvanic and electrolytic operation. International Journal of Hydrogen Energy 40, 9278-9286, doi:https://doi.org/10.1016/j.ijhydene.2015.05.162 (2015).

19 Bi, L., Shafi, S. P. \& Traversa, E. Y-doped $\mathrm{BaZrO}_{3}$ as a chemically stable electrolyte for proton-conducting solid oxide electrolysis cells (SOECs). Journal of Materials Chemistry A 3, 5815-5819, doi:10.1039/C4TA07202B (2015).

20 Li, S. \& Xie, K. Composite Oxygen Electrode Based on LSCF and BSCF for Steam Electrolysis in a Proton-Conducting Solid Oxide Electrolyzer. Journal of The Electrochemical Society 160, F224-F233, doi:10.1149/2.027303jes (2013).

21 Matsumoto, H., Sakai, T. \& Okuyama, Y. in Pure and Applied Chemistry Vol. 85427 (2012). 
22 Gan, Y. et al. Composite Oxygen Electrode Based on LSCM for Steam Electrolysis in a Proton Conducting Solid Oxide Electrolyzer. Journal of The Electrochemical Society 159, F763-F767, doi:10.1149/2.018212jes (2012).

23 Shang, M., Tong, J. \& O'Hayre, R. A promising cathode for intermediate temperature protonic ceramic fuel cells: $\mathrm{BaCo}_{0.4} \mathrm{Fe}_{0.4} \mathrm{Zr}_{0.2} \mathrm{O}_{3-\delta}$. RSC Advances 3, 15769-15775, doi:10.1039/C3RA41828F (2013).

24 Strandbakke, R. et al. Gd- and Pr-based double perovskite cobaltites as oxygen electrodes for proton ceramic fuel cells and electrolyser cells. Solid State Ionics 278, 120-132, doi:http://dx.doi.org/10.1016/j.ssi.2015.05.014 (2015).

25 Poetzsch, D., Merkle, R. \& Maier, J. Proton conductivity in mixed-conducting BSFZ perovskite from thermogravimetric relaxation. Physical Chemistry Chemical Physics 16, 16446-16453 (2014).

26 Zohourian, R., Merkle, R. \& Maier, J. Proton uptake into the protonic cathode material $\mathrm{BaCo}_{0.4} \mathrm{Fe}_{0.4} \mathrm{Zr}_{0.2} \mathrm{O}_{3-\delta}$ and comparison to protonic electrolyte materials. Solid State Ionics 299, 64-69 (2017).

27 Strandbakke, R., Vøllestad, E., Robinson, S. A., Fontaine, M.-L. \& Norby, T. $\mathrm{Ba}_{0.5} \mathrm{Gd}_{0.8} \mathrm{La}_{0.7} \mathrm{Co}_{2} \mathrm{O}_{6-\delta}$ Infiltrated in Porous $\mathrm{BaZr}_{0.7} \mathrm{Ce}_{0.2} \mathrm{Y}_{0.1} \mathrm{O}_{3}$ Backbones as Electrode Material for Proton Ceramic Electrolytes. Journal of The Electrochemical Society 164, F196-F202, doi:10.1149/2.0141704jes (2017).

28 Vollestad, E., Schrade, M., Segalini, J., Strandbakke, R. \& Norby, T. Relating defect chemistry and electronic transport in the double perovsksite $\mathrm{Ba}_{1-\mathrm{x}} \mathrm{Gd}_{0.8} \mathrm{La}_{0.2+\mathrm{x}} \mathrm{Co}_{2} \mathrm{O}_{6-}$ $\delta$ (BGLC). Journal of Materials Chemistry A 5, 15743-15751, doi:10.1039/C7TA02659E (2017).

29 Brieuc, F., Dezanneau, G., Hayoun, M. \& Dammak, H. Proton diffusion mechanisms in the double perovskite cathode material $\mathrm{GdBaCo}_{2} \mathrm{O}_{5.5}$ : A molecular dynamics study. Solid State Ionics 309, 187-191, doi:10.1016/j.ssi.2017.07.017 (2017).

30 Mokkelbost, T. et al. High-Temperature Proton-Conducting Lanthanum Ortho-NiobateBased Materials. Part II: Sintering Properties and Solubility of Alkaline Earth Oxides. Journal of the American Ceramic Society 91, 879-886, doi:10.1111/j.15512916.2007.02232.x (2008).

31 Tong, J., Clark, D., Hoban, M. \& O'Hayre, R. Cost-effective solid-state reactive sintering method for high conductivity proton conducting yttrium-doped barium zirconium ceramics. Solid State Ionics 181, 496-503, doi:https://doi.org/10.1016/j.ssi.2010.02.008 (2010).

32 Kwon, O. H. \& Choi, G. M. Electrical conductivity of thick film YSZ. Solid State Ionics 177, 3057-3062, doi:https://doi.org/10.1016/j.ssi.2006.07.039 (2006).

33 Timakul, P., Jinawath, S. \& Aungkavattana, P. Fabrication of electrolyte materials for solid oxide fuel cells by tape-casting. Ceramics International 34, 867-871, doi:https://doi.org/10.1016/j.ceramint.2007.09.038 (2008).

34 Kim, S. J., Kim, K. J., Dayaghi, A. M. \& Choi, G. M. Polarization and stability of $\mathrm{La}_{2} \mathrm{NiO}_{4+\delta}$ in comparison with $\mathrm{La}_{0.6} \mathrm{Sr}_{0.4} \mathrm{Co}_{0.2} \mathrm{Fe}_{0.8} \mathrm{O}_{3-\delta}$ as air electrode of solid oxide electrolysis cell. International Journal of Hydrogen Energy 41, 14498-14506, doi:https://doi.org/10.1016/j.ijhydene.2016.05.284 (2016).

35 Jacobsen, T., Chatzichristodoulou, C. \& Mogensen, M. B. Fermi potential across working solid oxide cells with zirconia or ceria electrolytes. ECS Transactions 61, 203214 (2014).

36 Zhu, H. \& Kee, R. J. Membrane polarization in mixed-conducting ceramic fuel cells and electrolyzers. International Journal of Hydrogen Energy 41, 2931-2943, doi:https://doi.org/10.1016/j.ijhydene.2015.10.100 (2016). 
37 Kreuer, K. D. Proton-Conducting Oxides. Annual Review of Materials Research 33, 333-359, doi:10.1146/annurev.matsci.33.022802.091825 (2003).

38 Nikodemski, S., Tong, J. \& O'Hayre, R. Solid-state reactive sintering mechanism for proton conducting ceramics. Solid State Ionics 253, 201-210, doi:https://doi.org/10.1016/j.ssi.2013.09.025 (2013).

39 Ricote, S., Manerbino, A., Sullivan, N. P. \& Coors, W. G. Preparation of dense mixed electron- and proton-conducting ceramic composite materials using solid-state reactive sintering: BaCe0.8Y0.1M0.1O3- $\delta-\mathrm{Ce} 0.8 \mathrm{Y} 0.1 \mathrm{M} 0.1 \mathrm{O} 2-\delta(\mathrm{M}=\mathrm{Y}, \mathrm{Yb}, \mathrm{Er}, \mathrm{Eu})$. Journal of Materials Science 49, 4332-4340, doi:10.1007/s10853-014-8129-z (2014).

Acknowledgements: The work leading to these results has received funding from the Research Council of Norway (grant 236828), and from the European Union's Seventh Framework Programme (FP7/2007-2013) for the Fuel Cells and Hydrogen Joint Technology Initiative under grant agreement 621244 (“ELECTRA”) and Fuel Cells and Hydrogen 2 Joint Undertaking under grant agreement 779486 (“GAMER”). This Joint Undertaking receives support from the European Union's Horizon 2020 research and innovation programme, Hydrogen Europe and Hydrogen Europe research.

\section{Detailed author contributions}

E.V., R.S., M-L.F., J.M.S. and T.N., conceived, designed and supervised the research. D.B. prepared the tubular half-cells. M-L.F. prepared electrodes. E.V. and R.S. developed and synthesized the electrode materials, fabricated the electrolysers from tubular half-cells, and conducted electrochemical characterization. M.T. conducted stability and humidity tests. D.C. and J.M.S. was in charge of CFD calculations. Electrochemical model was made by E.V. TEM images and graphical processing was done by D.R.C. All authors contributed to writing the manuscript.

\section{Methods}

\section{Preparation of tubular half-cells}

The electrolyte material is $\mathrm{BaZr}_{0.7} \mathrm{Ce}_{0.2} \mathrm{Y}_{0.1} \mathrm{O}_{2.95}$ (BZCY72). Acceptor-doped $\mathrm{BaZrO}_{3}$ is the oxide material with the theoretically highest bulk conductivity of protons, ${ }^{37}$ while acceptordoped $\mathrm{BaCeO}_{3}$ is less chemically stable but has lower grain boundary resistance, giving a higher total proton conductivity. A solid solution of $\mathrm{BaZrO}_{3}$ and $20 \% \mathrm{BaCeO}_{3}$ renders a high performing electrolyte material, chemically stable in high steam pressures. In this process, the half-cells were prepared by co-sintering a coated, extruded substrate. 
Final thermal processing consisted of a reactive sintering method ${ }^{31,38,39}$ in which the final material is produced via decomposition of the component oxides during normal powder processing, rather than using single-phase doped barium zirconate powder. The extrudate consisted of a mixture of ceramic powder dispersed in an aqueous binder system. The ceramic component was a blend of $\mathrm{BaSO}_{4}$ (Solvay), $\mathrm{CeO}_{2}$ (American Elements), $\mathrm{ZrO}_{2}$ (AMR), $\mathrm{Y}_{2} \mathrm{O}_{3}$ (HJD International) adjusted such that the stoichiometric ratios would yield BZCY72 on decomposition along with $\mathrm{NiO}$ (Fuel Cell Materials). All powders but $\mathrm{NiO}$ were first attrition milled with an ammonium polyacrylate dispersant to an average particle size of $0.3 \mu \mathrm{m}$. NiO was used as-received with an average particle size of $1 \mu \mathrm{m}$. Following extrusion, the green substrate was coated with a slurry of milled perovskite precursors, binder and organic solvent.

The coated tubes were then sintered by hang-firing in a muffle furnace at 1600 to $1650^{\circ} \mathrm{C}$ for 5 to 10 hrs, which yields dense tubes of BZCY72/NiO with a nominally $30 \mu \mathrm{m}$ thick BZCY72 coating. The tubular cells presented herein are made from tubes taken from production batches sintered within this range (longer dwell times for lower temperatures and vice versa) without further specification for each tube. Subsequent reduction of the substrate was performed in a tube furnace at $1000^{\circ} \mathrm{C}$ using $5 \% \mathrm{H}_{2} /$ balance Ar. Open porosity of the substrate was estimated using the Archimedes method to be $25 \%$.

\section{Sintering of steam-side anodes}

Four different cells, one with a single-phase anode layer of BGLC ( $x=0.3$, Cell 1$)$ and three with composite anode layers of BGLC $(x=0.5)$ and BZCY (Cells 2-4) were prepared and tested on half-cells which was sealed to $\mathrm{Al}_{2} \mathrm{O}_{3}$ risers and capped in the open end by use of a glassceramic sealing material developed specifically for BZCY tubular ceramics by CoorsTek Membrane Sciences.

Cell 1: The assembly of riser, lower sealing ring, pre-reduced tube segment and sealing cap was mounted in a custom-made sealing jig in a ProboStat ${ }^{\mathrm{TM}}$ (NORECS, Norway) sample holder with an outer tube for controlled atmosphere and heated to $1000^{\circ} \mathrm{C}$ at $3 \%$ min in $5 \% \mathrm{H}_{2}$ in dry Ar. After dwelling for 1 hour at $1000^{\circ} \mathrm{C}$, the cell was sealed, and the temperature lowered to RT at $3 \%$ min. The single-phase anode was applied on the pre-reduced and sealed half-cell. Inhouse synthesized powders of $\mathrm{Ba}_{0.7} \mathrm{Gd}_{0.8} \mathrm{La}_{0.5} \mathrm{Co}_{2} \mathrm{O}_{6-\delta}$ (BGLC, $x=0.3$ ) was prepared by a derived Pechini synthesis route. The starting materials were: $\mathrm{BaCO}_{3}$ (99\% Alfa Aesar), $\mathrm{Gd}\left(\mathrm{NO}_{3}\right)_{3} \cdot 6 \mathrm{H}_{2} \mathrm{O}$ (99\%, Sigma-Aldrich), $\mathrm{La}\left(\mathrm{NO}_{3}\right)_{3} \cdot 6 \mathrm{H}_{2} \mathrm{O}\left(99 \%\right.$, Fluka) and $\mathrm{Co}\left(\mathrm{NO}_{3}\right)_{2} \cdot 6 \mathrm{H}_{2} \mathrm{O}$ (99\%, Sigma-Aldrich) in stoichiometric composition. 1.5 mole citric acid (99.5\%, Sigma- 
Aldrich) per mole cations was dissolved in water in a large beaker on a hot plate. $\mathrm{BaCO}_{3}$ was slowly added until fully dissolved upon magnetic stir. La-, Gd-, and Co nitrates were subsequently dissolved. The beaker was left on the hot-plate with magnetic stir for evaporation of the water. When a thick gel was obtained, the beaker was put in a (ventilated) heating cabinet at $250^{\circ} \mathrm{C}$ for $18 \mathrm{hrs}$ for the combustion reaction to take place. The combusted powder was crushed thoroughly in a mortar and calcined at $1100^{\circ} \mathrm{C}$ for $5 \mathrm{hrs}$. XRD confirmed single-phase.

The calcined powder was firstly ball-milled in isopropanol at $250 \mathrm{rpm}$ in an agate jar for two hrs and further ultra-sonicated for 3 minutes to break up agglomerates. The powder was dried in air for $1 \mathrm{hr}$, and finally mixed with a commercial Nextech ink vehicle and left on a magnetic stir for 20 hrs. After the stir-mixing, the ink was brush-painted in eight thin layers, with a drying step in air in between each coating, onto the pre-reduced sealed tube segment, mounted in a ProboStat ${ }^{\mathrm{TM}}$ sample holder and fired at $1000^{\circ} \mathrm{C}$ for $1 \mathrm{hr}$ with $2 \% \mathrm{O}_{2}$ in $\mathrm{Ar}$ in the outer compartment. The tube segment was primed with $\mathrm{NiO}$ sintering aid prior to electrode deposition and the inner tube compartment was kept in $5 \% \mathrm{H}_{2}$ in Ar during anode sintering. Due to the large chemical gradient across the cell, and the mixed electronic-ionic conduction behavior of BZCY at high temperatures and under dry oxidizing conditions, the electrolyte is expected to face significant oxygen flux in the anode sintering process. Therefore, to avoid Ni re-oxidation, the cell was supplied with Pt electrode wires, connected to a Gamry Ref-3000 potentiostat and kept under an imposed potential of $1.5 \mathrm{~V}$ during the firing program. After anode deposition, a layer of Au paint (Metalor) was applied as current collector and fired in dual atmosphere at $800^{\circ} \mathrm{C}$ for $1 \mathrm{hr}$ before the electrolysis experiments. The electrode area was $4.7 \mathrm{~cm}^{2}$.

Cells 2-4: The composite anodes were applied on un-reduced tube segments. 60 vol\% BGLC ( $x=0.5$, Marion Technologies, France) was mixed with 40 vol\% BZCY (CerPoTech, Trondheim, Norway) and ball-milled in isopropanol at $200 \mathrm{rpm}$ for $3 \mathrm{hrs}$ using agate jar and balls. The mixed powder was firstly dried in air and mixed with Nextech ink vehicle using a magnetic stirring plate for 20 hrs. Three un-reduced $6 \mathrm{~cm}$ tubular NiO/BZCY // BZCY halfcells were primed with $\mathrm{NiO}$ sintering aid. $\mathrm{NiO}$ powder was dispersed in isopropanol and the suspension was applied at the surface of the electrolyte and dried in air. The segments were brush-painted in seven layers with a drying step in air in between each coating and fired in air with a $10 \mathrm{hrs}$ dwell at $1200^{\circ} \mathrm{C}$. After firing of the anode layers, the adhesion and mechanical robustness of the anodes was tested by fastening and removing a rubber Scotch tape. As current collector, Pt ink was brush-painted on cells 2 and 4 and fired for 1 hour at $1050^{\circ} \mathrm{C}$. Cell 3 was painted with $\mathrm{Ag}$ ink and fired at $850^{\circ} \mathrm{C}$ for 2 hrs. After firing of Pt / Ag current collectors, the 
anode layers were infiltrated with a suspension of BGLC $(x=0.5)$ particles $(d<100 \mathrm{~nm})$ for enhanced catalytic activity. The infiltration suspension was prepared as described elsewhere. ${ }^{24}$ The un-reduced cells were then mounted and sealed to $\mathrm{Al}_{2} \mathrm{O}_{3}$ riser tubes before cathode reduction. The thermal expansion mismatch between $\mathrm{NiO}$ and the sealing materials requires that un-reduced cells must be sealed and reduced in one step. In the one-step sealing and reduction procedure, the cells were mounted in a ProboStat ${ }^{\mathrm{TM}}$ sample holder on risers with upper and lower sealing rings and ceramic cap in a custom-made sealing jig. The assembly was heated to $1000^{\circ} \mathrm{C}$ in dry air where all parts sealed. The atmosphere in the inner compartment was subsequently switched to $5 \% \mathrm{H}_{2}$ in $\mathrm{Ar}$ for $30 \mathrm{~min}$ and to $10 \% \mathrm{H}_{2}$ in $\mathrm{Ar}$ for another $30 \mathrm{~min}$, keeping the flow at $50 \mathrm{SCCM}$. After 1 hour, the temperature was lowered to $800^{\circ} \mathrm{C}$ at $0.5^{\circ} / \mathrm{min}$ and left for 40 hrs for to complete $\mathrm{NiO}$ reduction. To avoid oxygen transport, the cell potential was kept at $1.5 \mathrm{~V}$. Monitoring electrolytic current during the process gave control over the reduction, yielding reduced, crack-free and gas-tight cells.

Cell 5: A final tubular cell employing a composite BGLC/BZCY anode was fabricated using a slightly different approach that circumvents the in-situ sealing and reduction procedure used for cells 2-4. Here, a $20 \mu \mathrm{m}$ thick porous BZCY backbone was sintered onto the tubular halfcell, before the cell was reduced at $1000^{\circ} \mathrm{C}$ in $5 \% \mathrm{H}_{2}$. The reduced half-cell (with backbone) was then capped and sealed under reducing conditions using the same procedure as for cell 1 . Following the sealing procedure, the BGLC electrode was dip-coated into the backbone using a loaded gel solution containing a combination of dissolved precursor nitrates and the calcined powder. The coated cell was subsequently fired at $950^{\circ} \mathrm{C}$ for 5 hours in dual atmosphere $(10 \%$ $\mathrm{O}_{2}$ on anode side, $30 \% \mathrm{H}_{2}$ on cathode side) to avoid re-oxidation in the reduced Ni-support while keeping the BGLC phase oxidized.

\section{Set-up and instruments}

Steam electrolysis and electrochemical characterization was performed in a special-made experimental reactor designed for measurements with high steam pressures (up to 50 bar total). Mass flow controllers and back pressure regulators control and adjust the gas flow rates and partial pressures on either compartment. The gas (and liquid water) is fed through an evaporator before it enters a hot-box which can be heated up to $200^{\circ} \mathrm{C}$. A three-zone furnace and gas distribution lines are placed inside the hot-box, to ensure proper and uniform heat throughout the measurement system - avoiding any condensation of steam due to cold spots. Exhaust gas 
is passed through a condenser to extract excess water before the gas is further passed either into a micro gas chromatograph (Model 490, Varian) or vented.

Two different experimental setups were used to measure the single cells. A ProboStat ${ }^{\mathrm{TM}}$ measurement cell was modified to tolerate temperatures up to $165^{\circ} \mathrm{C}$ (up to 2 bar steam possible) and pressures up to 10 bar and employed for measurements of Cells 1-3. An in-house built measurement system based on steel tubing and Swagelok fittings was employed for Cell 4 to enable higher temperature tolerance, and thus higher steam pressures without water condensation.

Electrochemical measurements were conducted by use of a Gamry Ref-3000 electrochemical interface equipped with a Reference 30K Booster, allowing DC currents up to 30 A. Stepwise galvanostatic voltage measurements at increasing currents were performed under isothermal and isobaric conditions while the outlet gas composition was analysed in the micro GC. The outlet gas flow was recorded with reactor mass flow controllers and an extra digital flowmeter on the gas line between the reactor and the GC. The measurements were repeated for different temperatures and steam pressures. Impedance sweeps were taken in the frequency range from $10^{5}$ to $10^{-2} \mathrm{~Hz}$ at steady OCV, and before and after every current step, each time with the same DC bias as the corresponding galvanostatic step.

Cell 5 was used to measure the long-term stability in electrolysis operation and humidity of the hydrogen-side exhaust. Both experiments were conducted at $600^{\circ} \mathrm{C}$ with symmetrical total

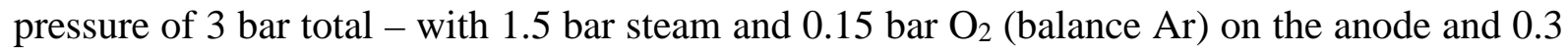
bar $\mathrm{H}_{2}$ (balance $\mathrm{Ar}$ ) on the cathode. The long-term stability tests were conducted over 700 hours at a constant current density of $62.5 \mathrm{~mA} \cdot \mathrm{cm}^{-2}$, with 0.03 bar of steam in the cathode sweep gas. For the humidity test, the applied current density varied from 0 to $60 \mathrm{~mA} \cdot \mathrm{cm}^{-2}$ and the steam concentration in the cathode exhaust gas was monitored by a Fischerbrand 11745843 humidity sensor. Relative humidity and temperature of the hydrogen produced were measured and recorded by a humidity sensor under atmospheric pressure, for either dry or humidified (0.03 bar $\mathrm{H}_{2} \mathrm{O}$ ) sweep gas on the cathode side. The water partial pressure was calculated based on the average atmospheric pressure on the test days, which were $101.6 \mathrm{kPa}$ and $102.1 \mathrm{kPa}$ respectively. 
Data Availability

The data that support the findings of this study are available from the corresponding author upon reasonable request. 